\title{
Cervical lordosis in asymptomatic individuals: a meta-analysis
}

\author{
Guang-Ming Guo ${ }^{1 \dagger}$, Jun Li ${ }^{1 \dagger}$, Qing-Xun Diao ${ }^{1 *}$, Tai-Hang Zhu', Zhong-Xue Song ${ }^{1}$, Yang-Yang Guo \\ and Yan-Zheng Gao ${ }^{2 *}$
}

\begin{abstract}
Background: Cervical lordosis has important clinical and surgical implications. Cervical spine curvature is reported with considerable variability in individual studies. The aim of this study was to examine the existence and extent of cervical lordosis in asymptomatic individuals and to evaluate its relationship with age and gender.

Methods: A comprehensive literature search was conducted in several electronic databases. Study selection was based on pre-determined eligibility criteria. Random effects meta-analyses were performed to estimate the proportion of asymptomatic individuals with lordosis and the effect size of cervical lordotic curvature in these individuals which followed metaregression analysis to examine the factors affecting cervical lordosis. Data from 21 studies (15,364 asymptomatic individuals, age 42.30 years [95\% confidence interval 36.42, 48.18], 54.2\% males) were used in the present study.

Results: In this population, 63.99\% [95\% confidence interval 44.94, 83.03] individuals possessed lordotic curvature. Degree of lordotic curvature differed by method of measurement; $12.71^{\circ}[6.59,18.84]$ with Cobb C2-C7 method and $18.55^{\circ}[14.48,22.63]$ with posterior tangent method. Lordotic curvature was not significantly different between symptomatic and asymptomatic individuals but was significantly higher in males in comparison with females. Age was not significantly associated with lordotic cervical curvature.
\end{abstract}

Conclusion: Majority of the asymptomatic individuals possesses lordotic cervical curvature which is higher in males than in females but have no relationship with age or symptoms.

Keywords: Cervical spine, Lordosis, Asymptomatic, Age, Gender

\section{Background}

Cervical lordosis is important for the efficiency of many processes including mastication, breathing, vocalization, eye movement, and gaze and for the shock absorption during walking and running [1]. Curvature of the cervical spine has important clinical implications [2, 3]. Attainment of moderate cervical lordotic curvature is found to be associated with better surgical outcomes in patients with neurologic deficits [4-6]. Reattainment of cervical lordosis after a surgical intervention is also considered important as compression of nervous tissue may cause injury otherwise [7].

\footnotetext{
*Correspondence: qxdiao_ortho@126.com; gairen513364872@163.com

${ }^{\dagger}$ Guang-Ming Guo and Jun Li contributed equally to this work.

'Department of Orthopaedics, Henan Zhoukou Union Orthopaedic Hospital, East Section, Taihao Road, Zhoukou 466000, Henan, China

2Department of Orthopaedics, Henan Province People's Hospital, Zhengzhou 450000, Henan, China
}

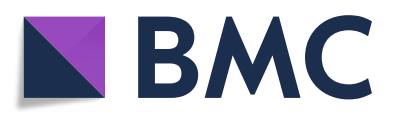

(c) The Author(s). 2018 Open Access This article is distributed under the terms of the Creative Commons Attribution 4.0 International License (http://creativecommons.org/licenses/by/4.0/), which permits unrestricted use, distribution, and reproduction in any medium, provided you give appropriate credit to the original author(s) and the source, provide a link to the Creative Commons license, and indicate if changes were made. The Creative Commons Public Domain Dedication waiver (http://creativecommons.org/publicdomain/zero/1.0/) applies to the data made available in this article, unless otherwise stated. around 10 weeks of fetal development [8] formed by the posterior wedging when height of vertebrae and discs at anterior side becomes greater than posterior side [1,9]. Cervical spine in asymptomatic individuals generally attains lordotic alignment but up to $35 \%$ of cases exhibit kyphosis [10]. Biomechanically, a lordotic configuration can resist large compressive loads [11] and minimize stress on the vertebral body endplates [12]. Cervical spine distributes the compressive load differently as compared with the rest of the spine; $36 \%$ of the compressive load is absorbed by the anterior column and $64 \%$ by the posterior facet joints $[13,14]$.

There are four reliable and predictive line drawing methods for the measurement of cervical lordosis on radiographs: Cobb $\mathrm{C} 2-\mathrm{C} 7$ method, Ishihara's index, Harrison $\mathrm{C} 2-\mathrm{C} 7$ posterior tangent method, and area 
under the curve [15]. Cobb method [16] was proposed for the evaluation of sagittal spinal curvature which was later modified by drawing vertebral endplate lines to construct angles on sagittal radiographs and is frequently used to evaluate cervical lordosis. Ishihara index is another way to measure curvature of the spine which is achieved by summing up the spinal lines connecting the posteroinferior corners of vertebra bodies and to construct additional orthogonal lines [17]. Harrison et al. [18] proposed a geometrical model for the measurement of cervical curvatures in sagittal radiographs which was later modified to an elliptical form to be usable for cervical lordosis as well [19]. There is a wide variation in the cervical lordotic curvature in asymptomatic individuals and patients with related conditions $[9,20,21]$. In asymptomatic individuals, average cervical lordosis is reported variably, e.g., 21.3 by Gore et al. [9], 22.3 by Owens et al. [22], and $34^{\circ}$ by Harrison et al. [18], depending also on the method used to measure the curvature.

Increase in lordosis with age is also reported by some studies $[9,23]$ but not all. Moreover, whereas some studies have found that a non-lordotic sagittal cervical curvature is not related to patient's initial symptoms [9], others have found that non-lordotic cervical curvature correlates with initial panic conditions [20, 21]. These varying observations necessitate having a systematic review of the relevant literature to have reliable estimates of normal lordotic cervical curvature and its affecting factors. The aim of present study was to review the studies which reported cervical curvature in healthy asymptomatic individuals after examining the radiographs with a reliable method, to synthesize the quantitative information pertaining to the cervical lordosis and its relationship with age and gender and morbidity.

\section{Methods}

\section{Eligibility criteria}

Studies were included if they met following criteria: study (1) included asymptomatic individuals either as sole study population or as controls to symptomatic patients to study normal measures of cervical lordosis, (2) provided values of $\mathrm{C} 2-\mathrm{C} 7$ lordosis angles and/or the proportion of individuals with lordotic curvature, and (3) included adult patients (above 18 years of age). Studies were excluded if (1) reported cervical lordosis measures other than global lordosis (C2-C7 angle), (2) reported segmental lordotic angles but not global lordosis, and (3) reported cervical lordosis measures without mentioning the symptomatic information of individuals/ patients.

\section{Search and selection of studies}

We searched Embase, Google Scholar, Ovid SP, and PubMed databases for relevant studies by using suitable
$\mathrm{MeSH}$ and keywords for research papers published before November 2016. The search was not restricted to language or period of publication. The following search terms and strategies were used: (1) cervical-lordosis OR curvature OR lordotic curvature OR alignment; (2) angle OR Cobb angle OR posterior tangent OR theta OR; (3) Radiograph OR X-ray OR Roentgenograph; and (4) various combinations of (1), (2), and (3).

Two reviewers conducted initial database search and independently screened the titles and abstracts identified in the initial search. This followed the observance of the inclusion and exclusion criteria as a result of which full text of articles were identified and later retrieved. If additional data or clarification was necessary, we contacted the study authors. Any disagreement between reviewers was resolved by discussion with other coauthors.

\section{Data and analyses}

The following information was collected from each study using a standardized form: study design and location, main inclusion/exclusion criteria, patient demographics, and study outcomes. Data were extracted by two reviewers independently. Cervical curvature measurements were considered if the study utilized either Cobb C2-7 angle (angle between the horizontal line of $\mathrm{C} 2$ lower endplate and the horizontal line of $\mathrm{C} 7$ lower endplate) or posterior tangent (angle formed by a line projected parallel to the posterior surface of $\mathrm{C} 2$ and a line parallel to the posterior surface of $\mathrm{C} 7$ ) method.

Statistical heterogeneity of the required data was tested with a chi-square test, and between-studies inconsistency was quantified by the $I^{2}$ index. Meta-analyses were carried out by using Stata software (version 12; Stata Corporation, USA) by pooling the $\mathrm{C} 2-\mathrm{C} 7$ angles reported in individual studies and to generate inverse variance weighted overall effect size as well as effect sizes with regard to method used for the measurement of the lordotic cervical curvature and percentage of asymptomatic individuals with lordotic cervical curvature.

Random effects model was used for the meta-analyses keeping in view significant heterogeneity of the meta-analyzable data. Further analyses were carried out to evaluate the symptomatic and gender differences in cervical lordotic curvature by performing meta-analyses of mean differences using RevMan software (version 5.3; Cochrane collaboration). Meta-regression analyses were also performed to evaluate the effect of age and gender on cervical lordotic curvature using restricted maximum likelihood method in Stata software.

\section{Results}

Twenty-one studies $[18,19,24-42]$ were selected by following the eligibility criteria (Fig. 1). In these studies, 15,364 asymptomatic or healthy individuals were 


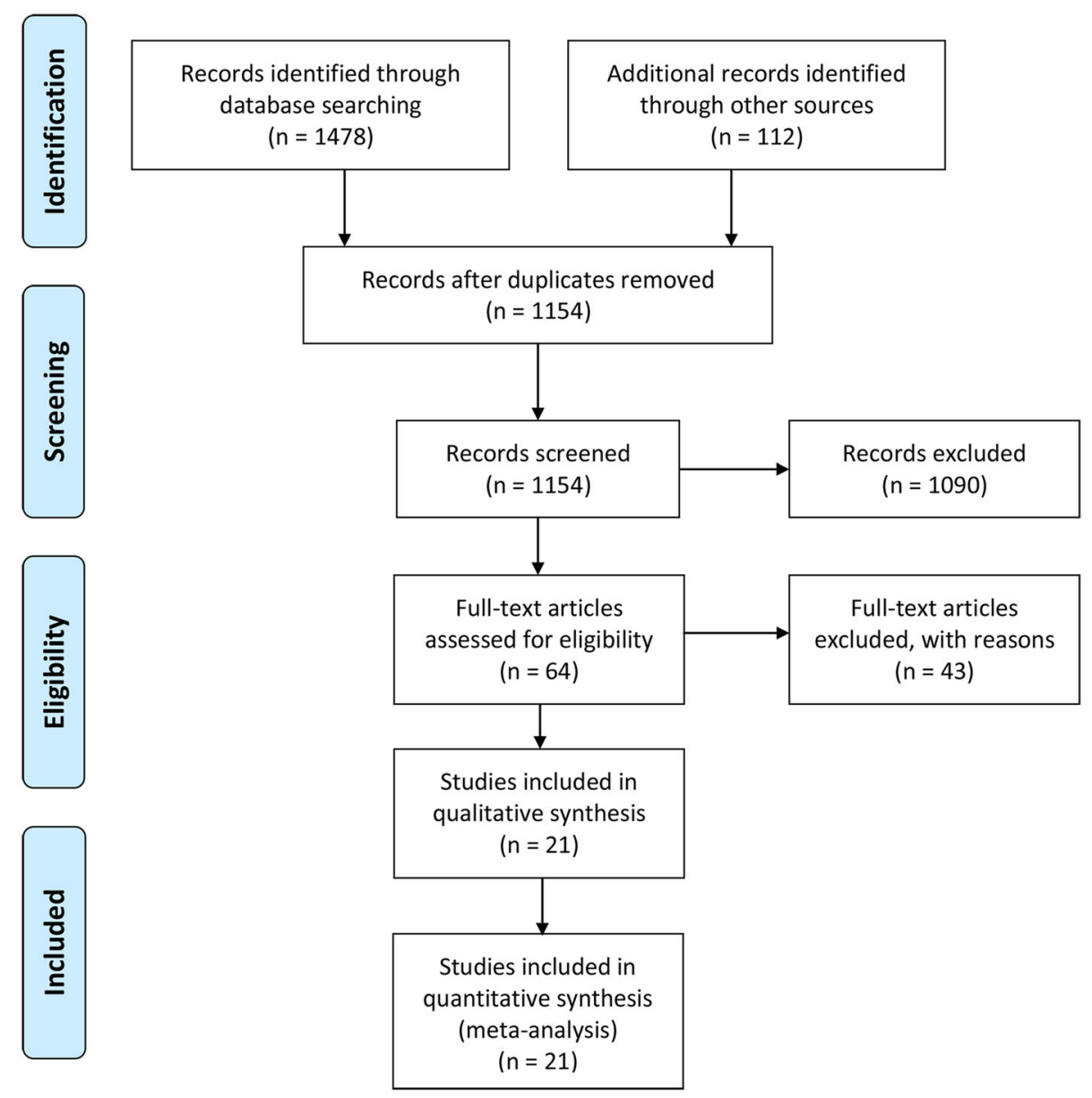

Fig. 1 A flowchart of study screening and selection process

recruited. Age (weighted average) of these individuals was 42.30 years [95\% confidence interval 36.42, 48.18], and $54.2 \%$ were males. Among the asymptomatic individuals studied, $63.99 \%$ [44.94, 83.03] had lordotic curvature while the rest had straight, kyphotic, or sigmoid curvature (dataset, 12455 asymptomatic individuals in 11 studies; Fig. 2).

Eleven of the included studies reported degree of cervical lordotic curvature in 3597 asymptomatic individuals. Overall, cervical lordotic curvature was found to be $16.43^{\circ}$ [95\% confidence interval $\left.12.69,20.17\right]$. However, cervical lordotic curvature differed by the method used. In 1046 asymptomatic individuals who underwent measurements with Cobb $\mathrm{C} 2-\mathrm{C} 7$ method, the curvature was found to be $12.71^{\circ}[6.59,18.84]$, whereas in 2551 asymptomatic individuals who underwent measurements with posterior tangent method, the cervical lordotic curvature was $18.55^{\circ}[14.48,22.63]$ (Fig. 3).

Lordotic cervical curvature was not significantly different between symptomatic and asymptomatic individuals (mean difference was $1.79^{\circ}[-4.08,7.67] ; p=0.55$; Fig. 4). However, lordotic cervical curvature was significantly higher in males in comparison with that in females (mean difference $4.4^{\circ}[1.63,7.17] ; p=0.002$; Fig. 5).

In the meta-regression analyses, age was not significantly associated with lordotic cervical curvature (coefficient $0.18[-0.19,0.56] ; p=0.314$ ) but was significantly associated with the percentage of individuals with lordotic cervical curvature (coefficient $1.43[0.20,2.66] ; p=$ 0.030; Fig. 6).

\section{Discussion}

This meta-analytical review finds that most asymptomatic individuals possess lordotic cervical curvature which averages at about $18^{\circ}$ when measured with $\mathrm{C} 2-\mathrm{C} 7$ posterior tangent method. However, Cobb $\mathrm{C} 2-\mathrm{C} 7$ method may underestimate as we have found that use of this method led to an average of about $13^{\circ}$ of lordotic cervical angle. We have also observed that there is no significant difference in cervical curvature between symptomatic and asymptomatic individuals but lordotic cervical curvature has been found to be significantly higher in men than in women. However, no significant relationship could be found between lordosis and age, 


\begin{tabular}{|c|c|c|c|c|}
\hline \multirow[b]{2}{*}{ Study } & \multirow{2}{*}{\multicolumn{2}{|c|}{$\mathrm{n}$}} & \multirow[b]{2}{*}{$\mathrm{ES}(95 \% \mathrm{Cl})$} & \multirow{2}{*}{$\begin{array}{l}\% \\
\text { Weight }\end{array}$} \\
\hline & & & & \\
\hline Borden 1960 & 180 & & - $90.80(89.41,92.19)$ & 9.09 \\
\hline Gore 2001 & 159 & & - $\quad 91.00(89.52,92.48)$ & 9.09 \\
\hline Grob 2007 & 53 & & $+96.00(93.36,98.64)$ & 9.08 \\
\hline Hald 1995 & 10922 & & - $89.30(89.12,89.48)$ & 9.10 \\
\hline Juhl 1962 & 116 & - : & $60.00(58.59,61.41)$ & 9.09 \\
\hline Kim 2015 & 46 & & $69.00(66.60,71.40)$ & 9.08 \\
\hline Le Huec 2015 & 106 & - & $53.00(51.61,54.39)$ & 9.09 \\
\hline Matsumoto 1998 & 495 & \% & $64.00(63.30,64.70)$ & 9.10 \\
\hline Takeshima 2002 & 204 & - & $23.50(22.83,24.17)$ & 9.10 \\
\hline Visscher 1998 & 54 & - & $39.00(37.33,40.67)$ & 9.09 \\
\hline Yu 2015 & 120 & - & $28.30(27.35,29.25)$ & 9.09 \\
\hline \multicolumn{2}{|c|}{ Overall (I-squared $=100.0 \%, p=0.000)$} & & $63.99(44.94,83.03)$ & 100.00 \\
\hline \multicolumn{2}{|c|}{ NOTE: Weights are from random effects analysis } & & & \\
\hline & -98.6 & \multicolumn{2}{|r|}{98.6} & \\
\hline
\end{tabular}

Fig. 2 A forest graph showing the percentage of asymptomatic individuals with lordotic cervical curvature and the overall effect size

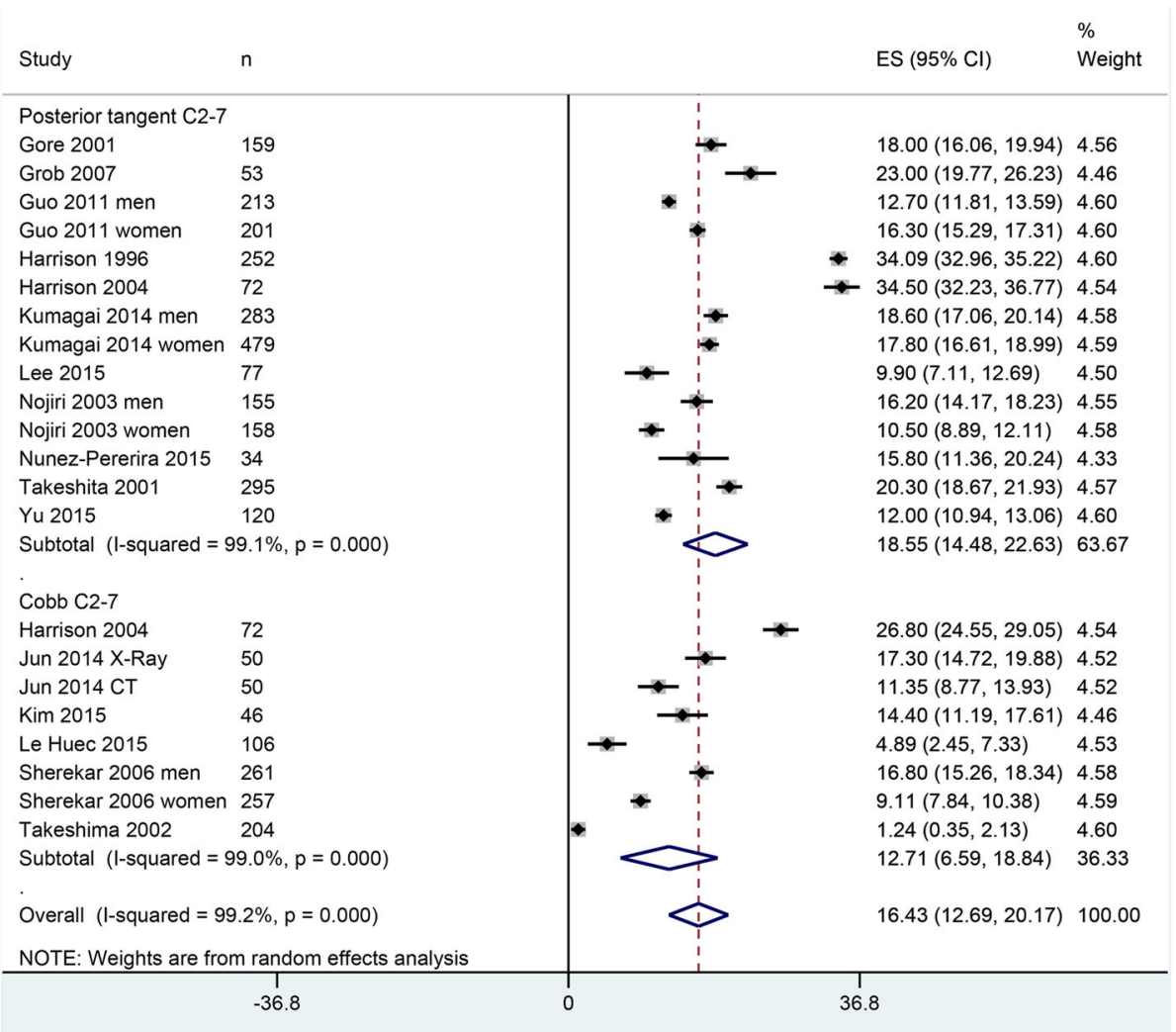

Fig. 3 A forest graph showing the cervical lordotic angles reported by individual studies and the overall effect size as well as the effect sizes of two methods used to measure the cervical curvature 


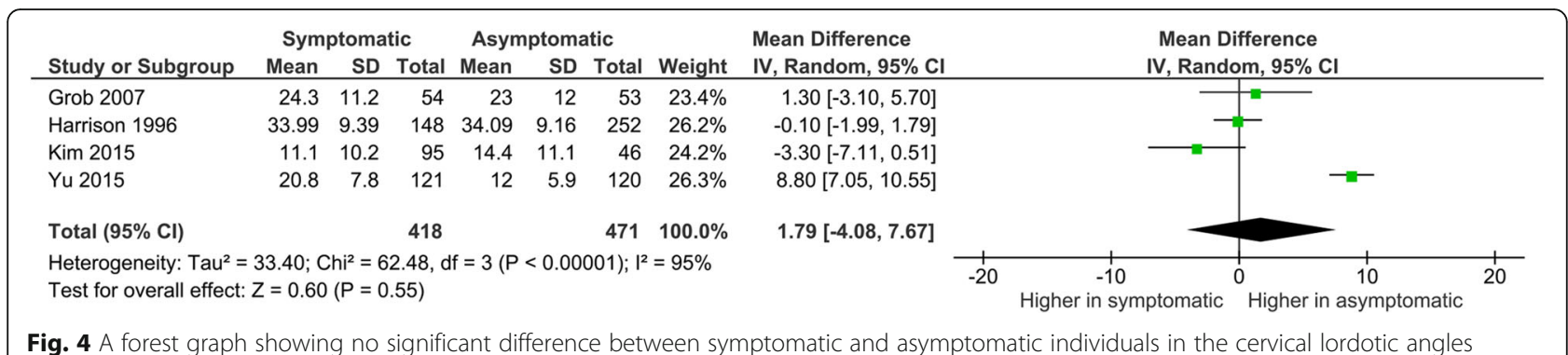

although the percentage of individuals with lordotic cervical curvature increased with age.

In a review study in which the authors analyzed data from studies which evaluated neutral upright sagittal spinal alignment from the occiput to the pelvis in asymptomatic adults, the greatest variation was noted in the cervical spine from $\mathrm{C} 2$ to $\mathrm{C} 7$ [43]. In this scenario, it becomes difficult to assess the effect of method on cervical curvature, although in a study in which both the methods were used simultaneously, lordotic angle values were found significantly higher with the posterior tangent $\mathrm{C} 2-\mathrm{C} 7$ method than with the Cobb C2C7 method [19]. A factor that is postulated to affect the level of cervical lordosis is the sagittal shape of odontoid dens [44, 45].

Although meta-regression analysis of the present study could not find a significant association between age and cervical lordotic curvature, increase in lordosis with age is reported by some studies [10, 23]. However, contradictory reports are also available in literature. Milne and Lauder [46], by using an indirect method (surveyor's flexicurve device) in a cross-sectional study of men and women aged 20-90 years, found an increase in kyphosis with age in both older men and women with no lordosis in an increasingly large proportion of both men and women over 60 years of age. Later, Harrison et al. [15] while comparing measurements with flexicurve and radiographic line methods, found that of the 96 flexicurve detected lordotic individuals, only 55 were found to have lordotic curvature on lateral radiographs. In the present study, we have found a positive relationship between the age and the percentage of individuals with lordotic curvature. However, our sample population belonged to rather a middle-aged group.

Lumbar lordosis, sacral inclination, and lumbosacral angulation show a tendency to decrease in individuals aged over 70 years [47]. Using a non-invasive measuring system in 323 asymptomatic individuals, Dreicharf et al. [48] found that total lordosis was significantly reduced by approximately $20 \%$ and the range of motion for maximal upper body flexion (RoF) by $12 \%$ and extension (RoE) by $31 \%$ in the oldest (50-75 years) compared to those in the youngest age cohort (20-29 years). During aging, the lower lumbar spine retains its lordosis and mobility, whereas the middle part flattens and becomes less mobile [48].

Such changes with age may put pressure on cervical spine to change simultaneously causing changes such as increase in lordosis seen by some authors. Whereas in healthy adults (aged 22-50 years), cervical sagittal alignment is found to be associated with thoracic sagittal alignment but not with lumbopelvic alignment [49] and cervical lordosis inversely correlates with thoracic kyphosis [50]; in elderly people, cervical curvature is affected by pelvic sagittal alignment [51]. Lumbar lordosis decreases, and thoracic kyphosis increases with age which results in a compensatory increase in cervical lordosis [10, 17].

Based on a limited data that could be gained under the eligibility criteria of the present study, there was no significant difference between symptomatic and asymptomatic individuals in lordosis angle of the cervical spine. However, this finding is compatible with several related reports. As reviewed by Lippa et al. [52], many studies

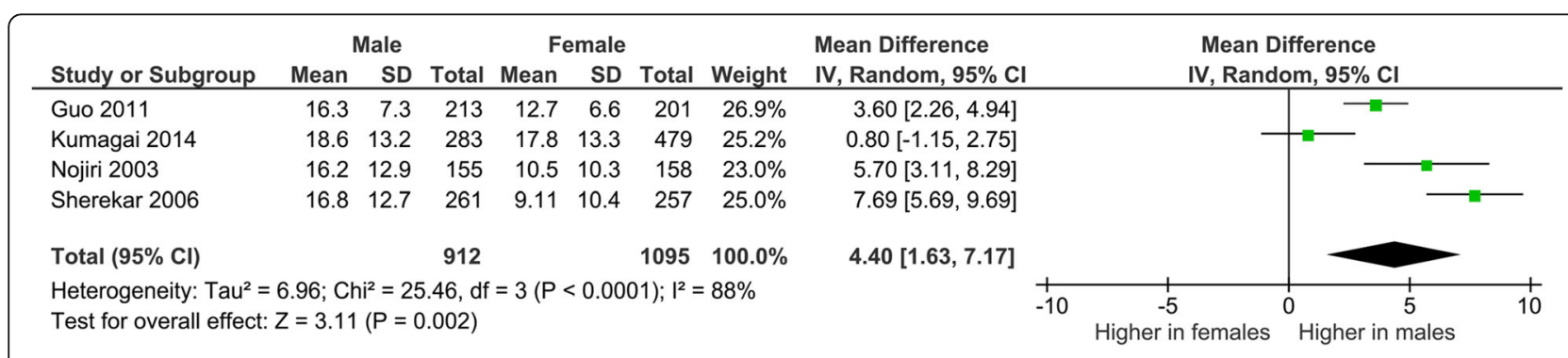

Fig. 5 A forest graph showing a significant difference in the cervical lordotic angles between male and female asymptomatic individuals 


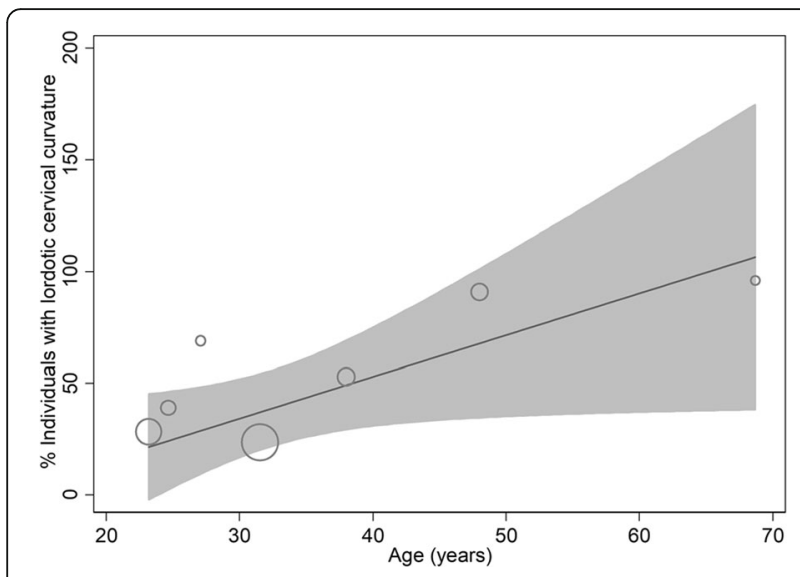

Fig. 6 A metaregression scatterplot showing the relationship between age and the percentage of individuals with lordotic curvature in cervical spine

have found no association between cervical lordotic curvature and symptoms especially the neck pain including whiplash injury in approximately 700 individuals [53-56]. Exceptions can also be found in literature. McAviney et al. [57], after examining 300 cervical X-rays in individuals with and without cervical pain, found a statistically significant association between cervical pain and lordosis of less than $20^{\circ}$ (posterior tangent method). However, in the present study, we have found that majority of the included studies which used the posterior tangent method reported less than $20^{\circ}$ cervical lordosis in asymptomatic individuals. Therefore, so far, evidence suggests that there exists no association between the degree of cervical lordosis and related symptoms. Even, there is some evidence to suggest that individuals with kyphotic cervical curvature may remain asymptomatic [54]. One of the weaknesses of the present study is that we could not perform subgroup analysis under hyperlordosis and hypolordosis categories. It was due to unavailability of categorical data in reports of the included studies. Only Harrison et al. described this as "The cervical lordosis in both acute and chronic neck pain patients was found to be hypolordotic." We did not try to categorize it because of a wide range of lordosis curvature in asymptomatic individuals and different degrees achieved by the use of two main methods in the included studies. Moreover, in general, we found no association between symptoms and lordosis angle.

\section{Conclusion}

Approximately $68 \%$ asymptomatic individuals possess lordotic cervical curvature. Average lordotic curvature is estimated at $18^{\circ}$ when $\mathrm{C} 2-\mathrm{C} 7$ posterior tangent method was used and $13^{\circ}$ with Cobb C2-C7 method. No significant difference in cervical curvature between symptomatic and asymptomatic individuals has been found, but lordotic cervical curvature was significantly higher in men than in women. No significant relationship was found between lordosis and age, but a positive relationship between the age and the percentage of individuals with lordotic curvature is observed.

\section{Authors' contributions \\ QXD and GMG were involved in the conception and design; JL and THZ analyzed data; ZXS and YYG contributed in the drafting of the manuscript and revised it critically; $Y Z G$ approved final version. All authors agreed to be accountable for all aspects of the work. All authors read and approved the manuscript.}

Ethics approval and consent to participate

Not applicable.

\section{Competing interests}

All authors declare that they have no competing interests.

\section{Publisher's Note}

Springer Nature remains neutral with regard to jurisdictional claims in published maps and institutional affiliations.

Received: 16 April 2018 Accepted: 1 June 2018

Published online: 15 June 2018

\section{References}

1. Been E, Shefi S, Soudack M. Cervical lordosis: the effect of age and gender. Spine J. 2017;17(6):880-8.

2. Kawakami M, Tamaki T, Yoshida M, Hayashi N, Ando M, Yamada H. Axial symptoms and cervical alignments after cervical anterior spinal fusion for patients with cervical myelopathy. J Spinal Disord. 1999;12:50-6.

3. Nightingale RW, McElhaney JH, Richardson WJ, Best TM, Myers BS Experimental impact injury to the cervical spine: relating motion of the head and the mechanism of injury. J Bone Joint Surg Am. 1996;78:412-21.

4. Baba H, Uchida K, Maezawa Y, Furusawa N, Azuchi M, Imura S. Lordotic alignment and posterior migration of the spinal cord following en bloc open-door laminoplasty for cervical myelopathy: a magnetic resonance imaging study. J Neurol. 1996;85:626-32.

5. Swank ML, Sutterlin CE, Bossons CR, Dials BE. Rigid internal fixation with lateral mass plates in multilevel anterior and posterior reconstruction of the cervical spine. Spine. 1997;22:274-82.

6. Stein J. Failure of magnetic resonance imaging to reveal the cause of a progressive cervical myelopathy related to postoperative spinal deformity: a case report. Am J Phys Med Rehabil. 1997;76:73-5.

7. Harrison DE, Cailliet R, Harrison DD, Janik TJ, Holland B. A new 3-point bending traction method for restoring cervical lordosis and cervical manipulation: a nonrandomized clinical controlled trial. Arch Phys Med Rehabil. 2002;83(4):447-53.

8. Bagnall KM, Harris PF, Jones PR. A radiographic study of the human fetal spine. I. The development of the secondary cervical curvature. J Anat. 1977; 123:777-82.

9. Broberg KB. On the mechanical behavior of the intervertebral disc. Spine. 1983:8:151-65.

10. Gore D, Sepic S, Gardner G. Roentgenographic findings of the cervical spine in asymptomatic people. Spine. 1986;11:521-4.

11. Miura T, Panjabi MM, Cripton PA. A method to simulate in vivo cervical spine kinematics using in vitro compressive preload. Spine. 2002;27:43-8.

12. Harrison DE, Harrison DD, Janik TJ, Jones EW, Cailliet R, Normand M. Comparison of axial and flexural stresses in lordosis and three buckled configurations of the cervical spine. Clin Biomech. 2001;16:276-84.

13. Albert TJ, Vacarro A. Postlaminectomy kyphosis. Spine (Phila Pa 1976). 1998; 23(24):2738-45.

14. Deutsch H, Haid RW, Rodts GE, Mummaneni PV. Postlaminectomy cervical deformity. Neurosurg Focus. 2003;15(3):E5

15. Harrison DE, Haas JW, Cailliet R, Harrison DD, Holland B, Janik TJ. Concurrent validity of flexicurve instrument measurements: sagittal skin contour of the cervical spine compared with lateral cervical radiographic measurements. J Manip Physiol Ther. 2005;28(8):597-603. 
16. Cobb J. Outline for the study of scoliosis. Am Acad Orthop Surg Instr Course Lect. 1948;5:261-75.

17. Ishihara A. Roentgenographic studies on the normal pattern of the cervical curvature. Nippon Seikeigeka Gakkai Zasshi. 1968;42:1033-44.

18. Harrison DD, Janik TJ, Troyanovich SJ, Holland B. Comparisons of lordotic cervical spine curvatures to a theoretical ideal model of the static sagittal cervical spine. Spine (Phila Pa 1976). 1996;21(6):667-75.

19. Harrison DD, Harrison DE, Janik TJ, Cailliet R, Ferrantelli JR, Haas JW, Holland B. Modeling of the sagittal cervical spine as a method to discriminate hypolordosis: results of elliptical and circular modeling in 72 asymptomatic subjects, 52 acute neck pain subjects, and 70 chronic neck pain subjects. Spine (Phila Pa 1976). 2004;29(22):2485-92.

20. Nagasawa A, Sakakibara T, Takahashi A. Roentgenographic findings of the cervical spine in tension-type headache. Headache. 1993;33:90-5.

21. Kai Y, Oyama M, Kurose S, Inadome T, Oketani Y, Masuda Y. Neurogenic thoracic outlet syndrome in whiplash injury. J Spinal Disord. 2001;14:487-93.

22. Owens E, Hoiris K. Cervical curvature assessment using digitized radiographic analysis. Chiropr Res J. 1990;4:47-62.

23. Kim HJ, Lenke LG, Oshima Y, Chuntarapas T, Mesfin A, Hershman S, et al, Cervical lordosis actually increases with aging and progressive degeneration in spinal deformity patients. Spine Deformity. 2014;2(5):410-4.

24. Borden AG, Rechtman AM, Gershon-Cohen J. The normal cervical lordosis, Radiology. 1960;74:806-9.

25. Gore DR. Roentgenographic findings in the cervical spine in asymptomatic persons: a ten-year follow-up. Spine (Phila Pa 1976). 2001;26(22):2463-6.

26. Grob D, Frauenfelder H, Mannion AF. The association between cervical spine curvature and neck pain. Eur Spine J. 2007;16(5):669-78.

27. Guo Q, Ni B, Yang J, Liu K, Sun Z, Zhou F, Zhang J. Relation between alignments of upper and subaxial cervical spine: a radiological study. Arch Orthop Trauma Surg. 2011;131(6):857-62.

28. Hald HJ, Danz B, Schwab R, Burmeister K, Bahren W. Radiographically demonstrable spinal changes in asymptomatic young men. Rofo. 1995; 163(1):4-8.

29. Juhl JH, Miller SM, Roberts GW. Roentgenographic variations in the normal cervical spine. Radiology. 1962;78:591-7.

30. Jun HS, Chang IB, Song JH, Kim TH, Park MS, Kim SW, Oh JK. Is it possible to evaluate the parameters of cervical sagittal alignment on cervical computed tomographic scans? Spine (Phila Pa 1976). 2014;39(10):E630-6.

31. Kim JH, Kim JH, Kim JH, Kwon TH, Park YK, Moon HJ. The relationship between neck pain and cervical alignment in young female nursing staff. J Korean Neurosurg Soc. 2015;58(3):231-5.

32. Kumagai G, Ono A, Numasawa T, Wada K, Inoue $R$, Iwasaki H, Iwane $K$, et al. Association between roentgenographic findings of the cervical spine and neck symptoms in a Japanese community population. J Orthop Sci. 2014; 19(3):390-7.

33. Le Huec JC, Demezon H, Aunoble S. Sagittal parameters of global cervical balance using EOS imaging: normative values from a prospective cohort of asymptomatic volunteers. Eur Spine J. 2015;24(1):63-71.

34. Lee SH, Son ES, Seo EM, Suk KS, Kim KT. Factors determining cervical spine sagittal balance in asymptomatic adults: correlation with spinopelvic balance and thoracic inlet alignment. Spine J. 2015;15(4):705-12.

35. Matsumoto M, Fujimura Y, Suzuki N, Toyama Y, Shiga H. Cervical curvature in acute whiplash injuries: prospective comparative study with asymptomatic subjects. Injury. 1998;29(10):775-8.

36. Nojiri K, Matsumoto M, Chiba K, Maruiwa H, Nakamura M, Nishizawa T, Toyama Y. Relationship between alignment of upper and lower cervical spine in asymptomatic individuals. J Neurosurg. 2003:99(1 Suppl):80-3.

37. Nunez-Pereira S, Hitzl W, Bullmann V, Meier O, Koller H. Sagittal balance of the cervical spine: an analysis of occipitocervical and spinopelvic interdependence, with C-7 slope as a marker of cervical and spinopelvic alignment. J Neurosurg Spine. 2015;23(1):16-23.

38. Sherekar SK, Yadav YR, Basoor AS, Baghel A, Adam N. Clinical implications of alignment of upper and lower cervical spine. Neurol India. 2006;54(3):264-7.

39. Takeshima T, Omokawa S, Takaoka T, Araki M, Ueda Y, Takakura Y. Sagittal alignment of cervical flexion and extension: lateral radiographic analysis. Spine (Phila Pa 1976). 2002;27(15):E348-55.

40. Takeshita K, Murakami M, Kobayashi A, Nakamura C. Relationship between cervical curvature index (Ishihara) and cervical spine angle (C2-7). J Orthop Sci. 2001;6(3):223-6.

41. Visscher CM, de Boer W, Naeije M. The relationship between posture and curvature of the cervical spine. J Manip Physiol Ther. 1998;21(6):388-91.
42. Yu M, Zhao WK, Li M, Wang SB, Sun Y, Jiang $L$, et al. Analysis of cervical and global spine alignment under Roussouly sagittal classification in Chinese cervical spondylotic patients and asymptomatic subjects. Eur Spine J. 2015; 24(6):1265-73.

43. Kuntz C 4th, Levin LS, Ondra SL, Shaffrey Cl, Morgan CJ. Neutral upright sagittal spinal alignment from the occiput to the pelvis in asymptomatic adults: a review and resynthesis of the literature. J Neurosurg Spine. 2007; 6(2):104-12.

44. Koebke J. Morphological and functional studies on the odontoid process of the human axis. Anat Embryol. 1979;155:197-208.

45. Johnson GM. The correlation between surface measurement of the head and neck posture and the anatomic position of the upper cervical vertebrae. Spine. 1998;23:921-7.

46. Milne JS, Lauder IJ. Age effects in kyphosis and lordosis in adults. Ann Hum Biol. 1974;1(3):327-37.

47. Amonoo-Kuofi HS. Changes in the lumbosacral angle, sacral inclination and the curvature of the lumbar spine during aging. Acta Anat (Basel). 1992; 145(4):373-7.

48. Dreischarf M, Albiol L, Rohlmann A, Pries E, Bashkuev M, Zander T, et al. Age-related loss of lumbar spinal lordosis and mobility - a study of 323 asymptomatic volunteers. PLoS One. 2014;9(12):e116186. https://doi.org/10. 1371/journal.pone.0116186.

49. Endo K, Suzuki H, Sawaji Y, Nishimura H, Yorifuji M, Murata K, et al. Relationship among cervical, thoracic, and lumbopelvic sagittal alignment in healthy adults. J Orthop Surg (Hong Kong). 2016;24(1):92-6.

50. Hardacker JW, Shuford RF, Capicotto PN, Pryor PW. Radiographic standing cervical segmental alignment in adult volunteers without neck symptoms. Spine (Phila Pa 1976). 1997;22:1472-80.

51. Strine TW, Hootman JM. US national prevalence and correlates of low back and neck pain among adults. Arthritis Rheum. 2007;57:656-65.

52. Lippa L, Lippa L, Cacciola F. Loss of cervical lordosis: what is the prognosis? J Craniovertebr Junction Spine. 2017;8(1):9-14.

53. Matsumoto M, Fujimura Y, Suzuki N, Toyama Y, Shiga H. Cervical curvature in acute whiplash injuries: prospective comparative study with asymptomatic subjects. Injury. 1998:29:775-8.

54. Grob D, Frauenfelder H, Mannion AF. The association between cervical spine curvature and neck pain. Eur Spine J. 2007;16:669-78.

55. Kumagai G, Ono A, Numasawa T, Wada K, Inoue R, Iwasaki H, et al. Association between roentgenographic findings of the cervical spine and neck symptoms in a Japanese community population. J Orthop Sci. 2014;19: 390-7.

56. Shilton M, Branney J, de Vries BP, Breen AC. Does cervical lordosis change after spinal manipulation for non-specific neck pain? A prospective cohort study. Chiropr Man Therap. 2015;23:33.

57. McAviney J, Schulz D, Bock R, Harrison DE, Holland B. Determining the relationship between cervical lordosis and neck complaints. J Manip Physiol Ther. 2005;28:187-93.

\section{Ready to submit your research? Choose BMC and benefit from:}

- fast, convenient online submission

- thorough peer review by experienced researchers in your field

- rapid publication on acceptance

- support for research data, including large and complex data types

- gold Open Access which fosters wider collaboration and increased citations

- maximum visibility for your research: over $100 \mathrm{M}$ website views per year

At BMC, research is always in progress.

Learn more biomedcentral.com/submissions 